\title{
Standard Modular Hydropower Technology Acceleration Workshop: Summary Report
}

Oak Ridge, TN

June 14-15, 2017

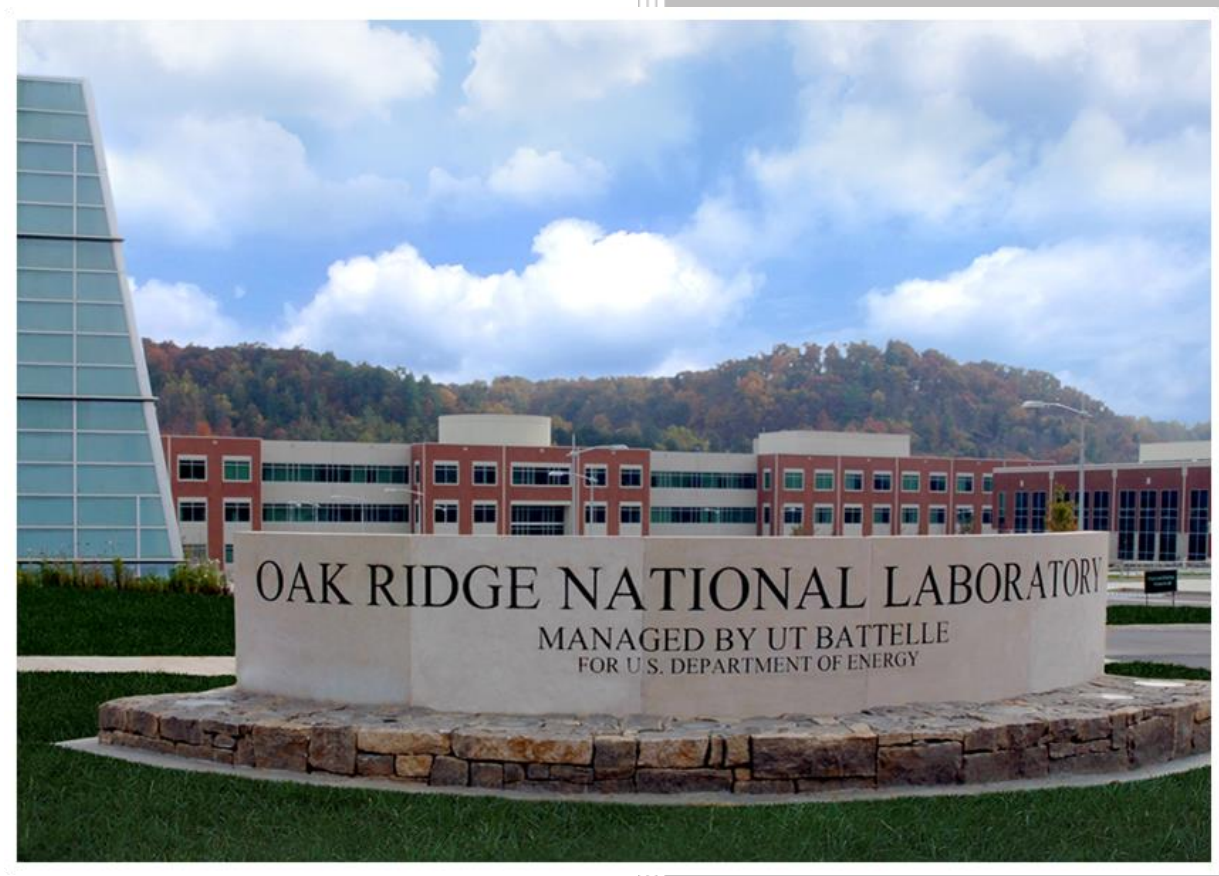

\section{Approved for public release.} Distribution is unlimited.
Adam Witt Miles Mobley Scott DeNeale Alisha Fernandez Brennan Smith

August 2017 


\section{DOCUMENT AVAILABILITY}

Reports produced after January 1, 1996, are generally available free via US Department of Energy (DOE) SciTech Connect.

Website http://www.osti.gov/scitech/

Reports produced before January 1, 1996, may be purchased by members of the public from the following source:

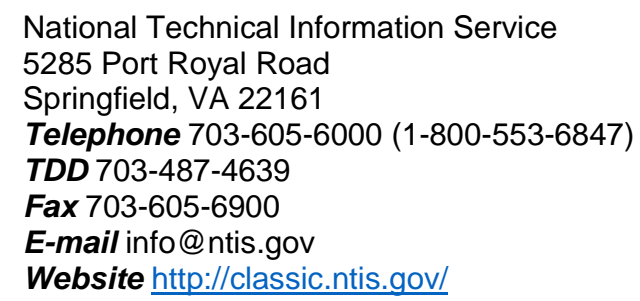

Reports are available to DOE employees, DOE contractors, Energy Technology Data Exchange representatives, and International Nuclear Information System representatives from the following source:

Office of Scientific and Technical Information

PO Box 62

Oak Ridge, TN 37831

Telephone 865-576-8401

Fax 865-576-5728

E-mail reports@osti.gov

Website http://www.osti.gov/contact.html

This report was prepared as an account of work sponsored by an agency of the United States Government. Neither the United States Government nor any agency thereof, nor any of their employees, makes any warranty, express or implied, or assumes any legal liability or responsibility for the accuracy, completeness, or usefulness of any information, apparatus, product, or process disclosed, or represents that its use would not infringe privately owned rights. Reference herein to any specific commercial product, process, or service by trade name, trademark, manufacturer, or otherwise, does not necessarily constitute or imply its endorsement, recommendation, or favoring by the United States Government or any agency thereof. The views and opinions of authors expressed herein do not necessarily state or reflect those of the United States Government or any agency thereof. 
Environmental Sciences Division

\title{
STANDARD MODULAR HYDROPOWER TECHNOLOGY ACCELERATION WORKSHOP: SUMMARY REPORT \\ OAK RIDGE, TN \\ June 14-15, 2017
}

\author{
Adam Witt \\ Miles Mobley \\ Scott DeNeale \\ Alisha Fernandez \\ Brennan Smith
}

Date Published: August 2017

Prepared by

OAK RIDGE NATIONAL LABORATORY

Oak Ridge, TN 37831-6283

managed by

UT-BATTELLE, LLC

for the

US DEPARTMENT OF ENERGY

under contract DE-AC05-00OR22725 



\section{CONTENTS}

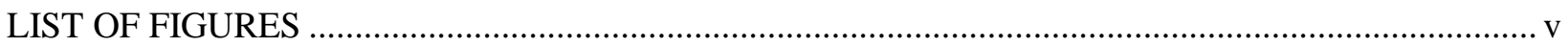

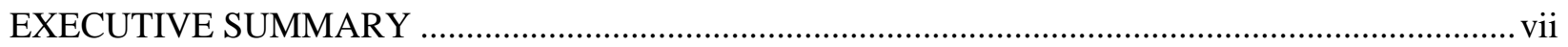

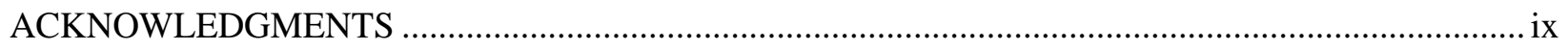

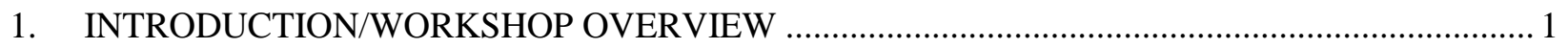

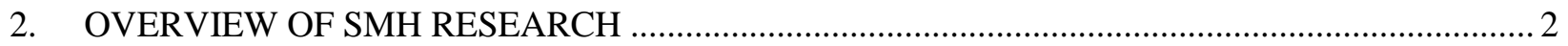

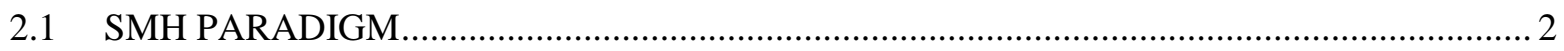

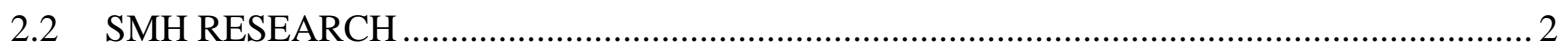

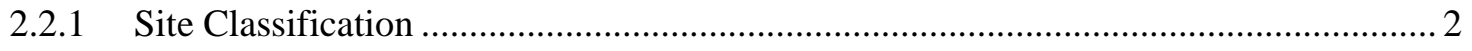

2.2.2 Exemplary Design Envelope Specification (EDES) …........................................... 3

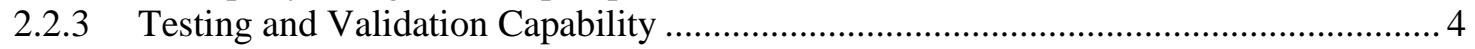

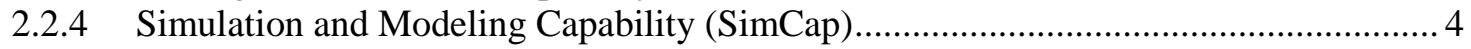

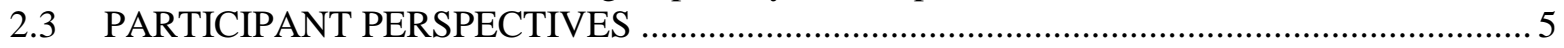

2.3.1 Amjet Turbine Systems - Technology innovator ..................................................... 5

2.3.2 Cadens, LLC - Technology innovator ................................................................... 6

2.3.3 Littoral Power Systems - Technology innovator and project developer ..................... 6

2.3.4 Natel Energy - Technology innovator, OEM, and project developer............................. 6

2.3.5 Rickly Hydrological Company - Technology innovator, OEM, and project

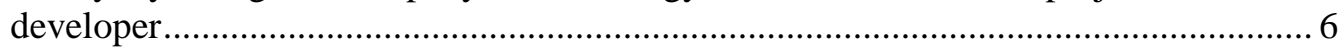

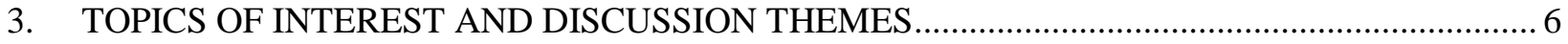

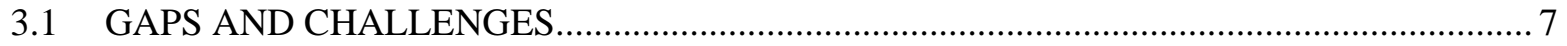

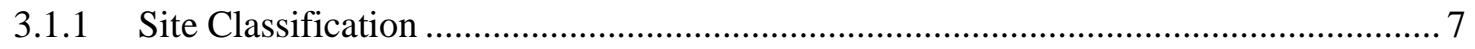

3.1.2 Module and Facility Design and Operation ..................................................... 7

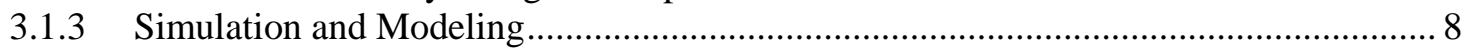

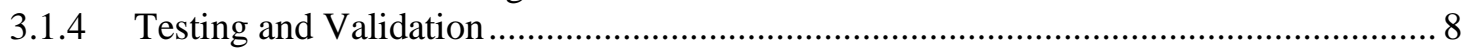

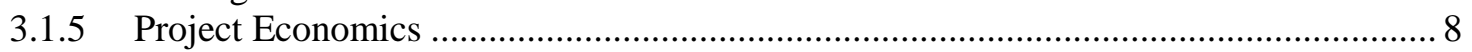

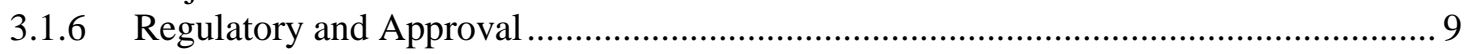

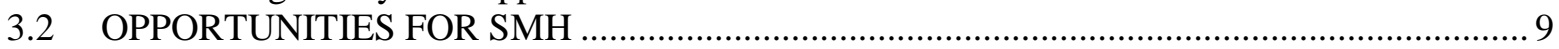

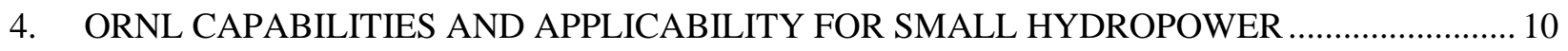

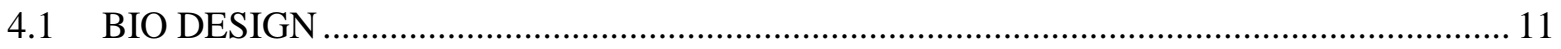

4.2 POWER ELECTRONICS AND ELECTRIC MACHINERY .............................................. 11

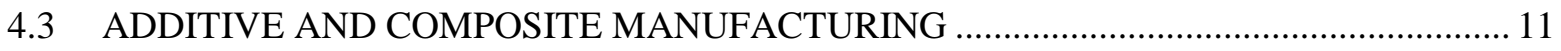

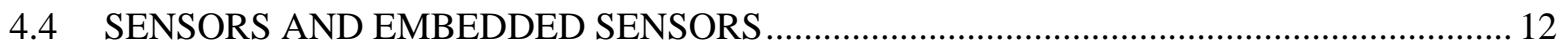

4.5 COMPUTATIONAL ENGINEERING AND ENERGY SCIENCES .................................. 12

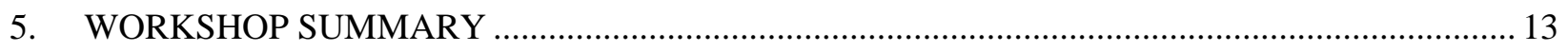

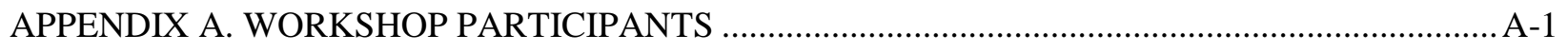

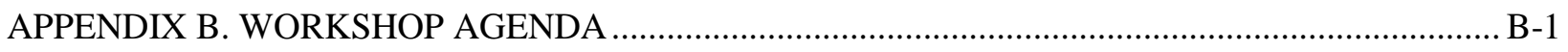





\section{LIST OF FIGURES}

Figure 1. Example of water quality clusters identified in the site classification research......................... 3

Figure 2. Example of exemplary design envelope specification for upstream fish passage modules. .

Figure 3. SimCap Flowchart.

Figure 4. Examples of BioDesign laboratory experiments to assess fish injury due to turbine 5. Examples of AM being used in small hydropower development.

Figure 5. Examples of AM being used in small hydropower development. .......................................... 12

Figure 6. Workshop Day 1 participants. 



\section{EXECUTIVE SUMMARY}

In support of the Department of Energy (DOE) funded Standard Modular Hydropower (SMH) Technology Acceleration project, Oak Ridge National Laboratory (ORNL) staff convened with five small hydropower technology entrepreneurs on June 14 and 15, 2017 to discuss gaps, challenges, and opportunities for small modular hydropower development. The workshop was designed to walk through SMH concepts, discuss the SMH research vision, assess how each participant's technology aligns with SMH concepts and research, and identify future pathways for mutually beneficial collaboration that leverages ORNL expertise and entrepreneurial industry experience. The goal coming out of the workshop is to advance standardized, scalable, modular hydropower technologies and development approaches with sustained and open dialogue among diverse stakeholder groups.

\section{Gaps and Challenges from Workshop Participants}

- Early-phase Site Assessments: Insufficient resolution of streamflow and environmental design criteria in early-phase site classification to inform site specific design models, parametrize stream functions, and enable formulaic and standardized plant design

- $\quad$ Additive Manufacturing: Uncertainty in how to best harness the benefits of additive manufacturing for small hydropower, e.g. 3D printing small components within the turbine module vs 3D printing an entire turbine runner and housing

- $\quad$ Testing and Validation: Limited mechanisms are available for testing, validating, and demonstrating new technologies

- Design Standards: Establishing and meeting certification/testing standards for divergent new technologies - how do SMH designs and facilities demonstrate they can achieve the same functionality as conventional and well-accepted technologies?

- Project Economics: Intake gates/racks/screens currently require site-specific design, resulting in a significant source of economic and performance uncertainty for small hydropower developers

\section{Opportunities for SMH and ORNL/Industry Collaboration}

- Standard Electrical Properties: Identify and assess high-potential opportunities for new modular development, including 'behind-the-meter' installations that tie-in at $480 \mathrm{~V}$ where off-the-shelf electrical equipment is readily available, standardized, and can be installed at a lower cost by most certified electricians

- Flow Control: Assess the potential for low-cost flow control for generation modules and for controlling flow over passage modules (fish, spillway, recreation, etc.)

- Case Studies: Develop case studies to provide technology developers with benchmark design specifications across multiple types of SMH-like sites with the goal of assessing scalability of modules and economic viability

- $\quad$ Additive Manufacturing: Move towards broader utilization of additive manufacturing in small hydropower by harnessing the advanced manufacturing capabilities of the ORNL manufacturing demonstration facility 
- Optimization Tools: Leverage high performance computing power at ORNL to develop design optimization tools for additively manufactured generation modules

- Broad Collaboration: Multi-lateral collaboration to develop standardized and scalable gate, fish screen, debris, and trash rack designs for low-head generation modules

- $\quad$ Moving SMH Forward: Establish working groups for individual modules to build cohesion among experts, develop tools to advance the state-of-the-art, and identify critical pathways towards modular facility deployment

ORNL staff received positive feedback regarding the workshop logistics, structure, content, and discussion. A deliberate effort was made to ensure workshop participants communicated openly with each other, that they shared knowledge gaps and ideas for modular development, and that they were aware of the entire spectrum of the SMH research vision, from site identification through design to testing.

To advance standardized, scalable, modular hydropower technologies, participants were unanimous that a sustained and open dialogue among diverse stakeholder groups is a necessary and essential requirement. Formal dialogue facilitated through webinars, module-specific workshops or working groups, a consortium of modular hydropower developers, and/or case studies that incorporate standardization, modularity, and environmental design for small hydropower will help advance SMH research and development concepts, refine technology innovators products, and inform the broader hydropower community about new opportunities for development. 


\section{ACKNOWLEDGMENTS}

The authors would like to acknowledge and express their appreciation to all the following individuals and programs for their review, comments, and support of this report and logistical support of the Standard Modular Hydropower Technology Acceleration Workshop.

\section{Oak Ridge National Laboratory}

- Missy Miller, Senior Administrator

- Shelaine Curd, Technical Project Leader

- Mark Bevelhimer, Senior Scientist

- Kevin Stewart, Water Resources Engineer

- William Tingen, SULI Participant

- Josh Benjamin, GEM Participant

- Hailey Russell, HERE participant 



\section{INTRODUCTION/WORKSHOP OVERVIEW}

In support of the US Department of Energy (DOE) Water Power Technologies Office (WPTO), Oak Ridge National Laboratory (ORNL) hosted small hydropower technology developers for a two-day workshop on June 14 and 15, 2017, as part of the Standard Modular Hydropower (SMH) Technology Acceleration research project. The purpose of the workshop was to

- Establish a common understanding of standardization, modularity, and environmental design concepts;

- Identify knowledge gaps between ORNL research activities and industry experience;

- Learn about advanced national laboratory capabilities that can be applied to small hydropower technology development, and;

- Identify high-impact collaboration pathways between ORNL and industry.

Workshop participants included industry representatives from five small hydropower technology development companies, ORNL staff from across the Energy and Environmental Sciences Directorate, Computing and Computational Sciences Directorate, Science and Technology Partnerships Directorate, and ORNL hydropower contractors. Participants' experience in small hydropower ranged from several years to decades, with expertise in project ownership, operation, design, product development, fish biology, hydropower markets, water resources engineering, civil engineering, and mechanical engineering (see Appendix A for a list of participants and Appendix B for the full workshop agenda).

Brennan Smith (ORNL Energy-Water Resource Systems [EWRS] group leader) welcomed the attendees to ORNL and gave an overview of ORNL's organizational hierarchy and EWRS research areas of expertise. He explained how the genesis of the SMH project was the 2015 New Pathways for Hydropower report $^{1}$ that explored potential paths for new hydropower development. He outlined how collaboration between ORNL and industry can help solidify a creative space where SMH research and development can thrive. He concluded his introduction by describing how the SMH research project is structured, emphasizing that identification and preservation of stream functionality is a necessary and guiding principle of SMH thinking.

Adam Witt (SMH principal investigator) introduced the workshop as a forum to help synthesize knowledge from industry and ORNL, and suggested that crosstalk (i.e., two-way communication among stakeholders and between ORNL and stakeholders) was encouraged. He went over the workshop objectives and the long-term vision of SMH. After a brief run-through of the agenda and workshop logistics, he laid out the ground rules of the workshop: (1) be respectful of time limits on the agenda, (2) encourage respectful, candid and constructive discussions, and (3) all participants are encouraged to use the "Parking lot" - a space to capture good ideas that need further discussion beyond the scope of the workshop. Afterward, participants gave brief introductions about their background and what excites them about new hydropower development.

${ }^{1} \underline{\text { http://hydropower.ornl.gov/docs/pubs/New_Pathways_for_Hydropower_Getting_Hydropower_Built_What_Does_it_Take.pdf }}$ 


\section{OVERVIEW OF SMH RESEARCH}

A series of brief presentations were prepared by ORNL staff to describe the SMH paradigm and provide additional detail on the SMH research structure. These presentations helped familiarize workshop attendees with SMH concepts and terminology and provided an overview of SMH.

\subsection{SMH PARADIGM}

Adam Witt began the overview of the SMH Paradigm by displaying the 2014 New Stream-reach Development (NSD) resource assessment ${ }^{2}$ map to highlight how ORNL's National Hydropower Asset Assessment Project (NHAAP) has formed the foundation of our current knowledge of small hydropower opportunities. The NSD resource assessment approximates $30 \mathrm{GW}$ of potential small hydropower plant (SHP) capacity at roughly 10,000 sites. SHP was defined broadly as plants with less than $10 \mathrm{MW}$ of capacity. Of these potential sites, most are low head $(<30 \mathrm{ft})$ sites with diverse environmental attributes. He explained how low-head sites developed using a conventional dam-impoundment methodology are expensive to develop, they have complex impacts on stream hydrology, geomorphology, water quality, and ecology, and as such, they generally require custom or site-specific studies, technologies, and reviews. As such, he suggested new and disruptive technologies (i.e., SMH) are needed to sustainably tap into this available energy source. Adam emphasized the need to shift from site-specific design to a standardized method of site assessment, technology design, and technology and facility assessment.

Upon inquiry, Adam informed the industry participants of the availability of the raw NSD data and how they could obtain it through NHAAP. Brennan Smith informed the participants that the NSD sites identified in the effort are all upper limit approximations and explained the appropriate uses of the data.

\subsection{SMH RESEARCH}

Adam Witt explained the basic SMH research structure and introduced the four SMH research pillars: site classification, exemplary design envelope specification, simulation and modeling capabilities, and testing and validation capabilities. Each pillar was explained in detail by the pillar lead.

\subsubsection{Site Classification}

Mark Bevelhimer (Site Classification Pillar lead) described how SMH research seeks to classify stream reaches by grouping them into clusters based on similar environmental characteristics, such as streamflow magnitude, water quality, and types of sediment. The idea is that a finite number of clusters, where each cluster contains 500 to 50,000 stream reaches, can be used to identify similarities across multiple potential sites to standardize design requirements for a module type (e.g., water quality, sediment passage, fish passage). A standard module may be applicable at many different sites within a cluster, enabling site-tosite scalability of standard designs.

The statistical method employed is a K-means clustering technique that uses environmental and other variables with national data coverage (e.g., flow, gradient, land use, population density) to establish a finite group of clusters with statistically similar characteristics. Mark displayed preliminary results in the form of a national map showing the spatial distribution of ten clusters of stream reaches with similar water quality characteristics (Figure 1). The results often reveal regional similarities in the underlying variables used in the statistical analysis.

\footnotetext{
${ }^{2}$ http://nhaap.ornl.gov/sites/default/files/ORNL_NSD_FY14_Final_Report.pdf
} 


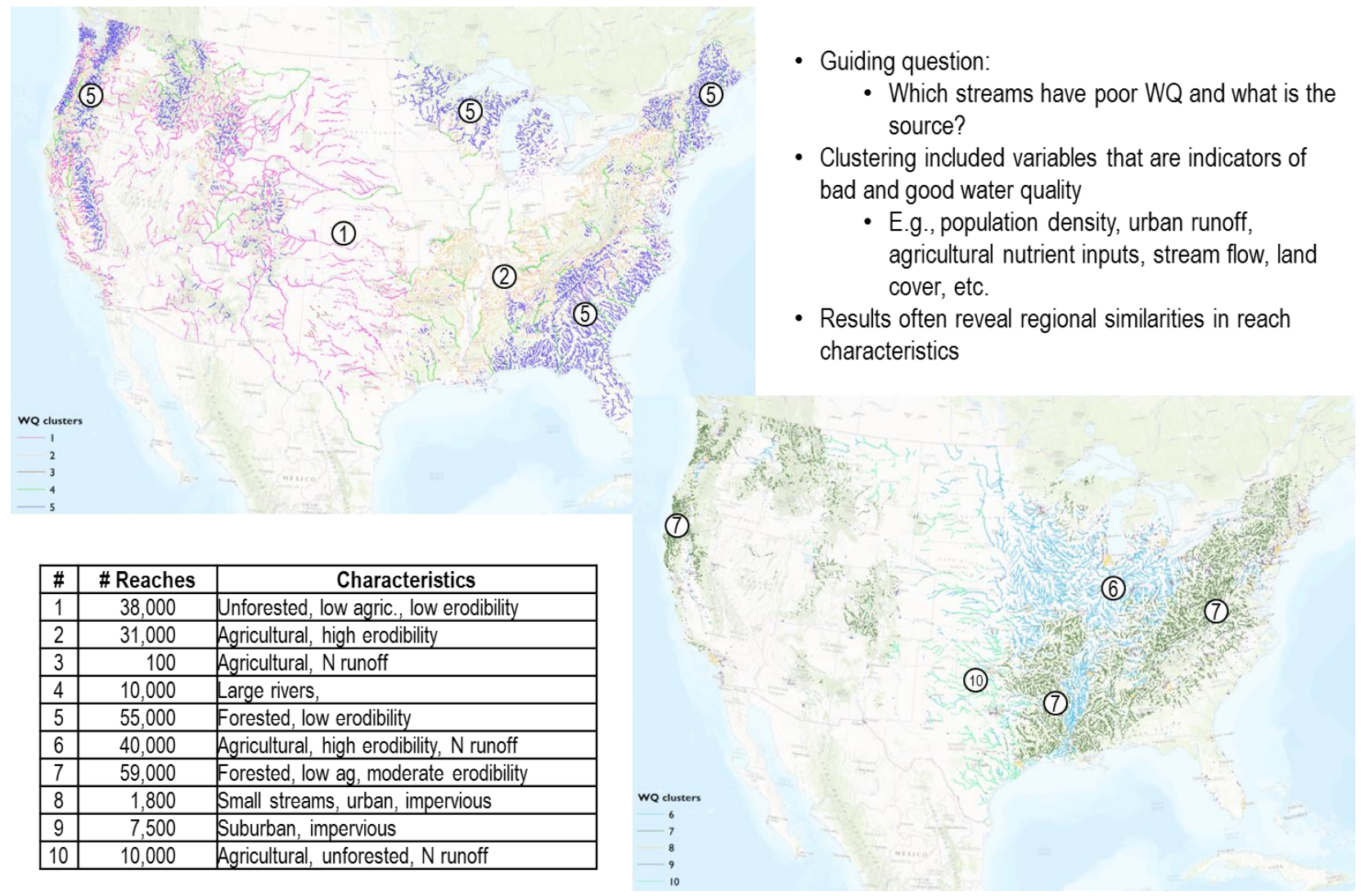

Figure 1. Example of water quality clusters identified in the site classification research.

The presentation initiated dialogue with participants on how to best define the nexus of research and project development, e.g., how can the results of site classification be made into useful and accessible tools for project and technology developers. Participants also expressed interest in expanding this effort to include non-powered dams (NPDs). Dialogue continued with how SMH should be able to identify existing environmental issues to ensure projects do not inherit pre-existing problems. This sort of identification may also provide an opportunity for SMH to target degraded watersheds and offer cobenefits such as restored fish passage, water quality improvements, and groundwater recharge.

\subsubsection{Exemplary Design Envelope Specification (EDES)}

Adam Witt provided an overview of the Exemplary Design Envelope Specification ${ }^{3}$ (EDES) pillar. He explained how EDES specifies the design objectives, requirements, constraints, and performance that align module functionality with stream reach characteristics identified through site classification. The EDES is technology agnostic in that it describes what a module should accomplish with its functionality, but not how it should be designed to achieve that functionality. For a module to be standard, it must deliver specific functionality at many stream-reaches with little or no modification to its design features. ORNL intends to work with industry to develop and advance modules that fit within the "design envelope." Figure 2 provides an example set of EDES objectives, requirements, constraints, and performance metrics for an upstream fish passage module.

\footnotetext{
${ }^{3}$ http://hydropower.ornl.gov/smh/docs/ORNL-SMH-Exemplary-Design-Envelope-Specification.pdf
} 


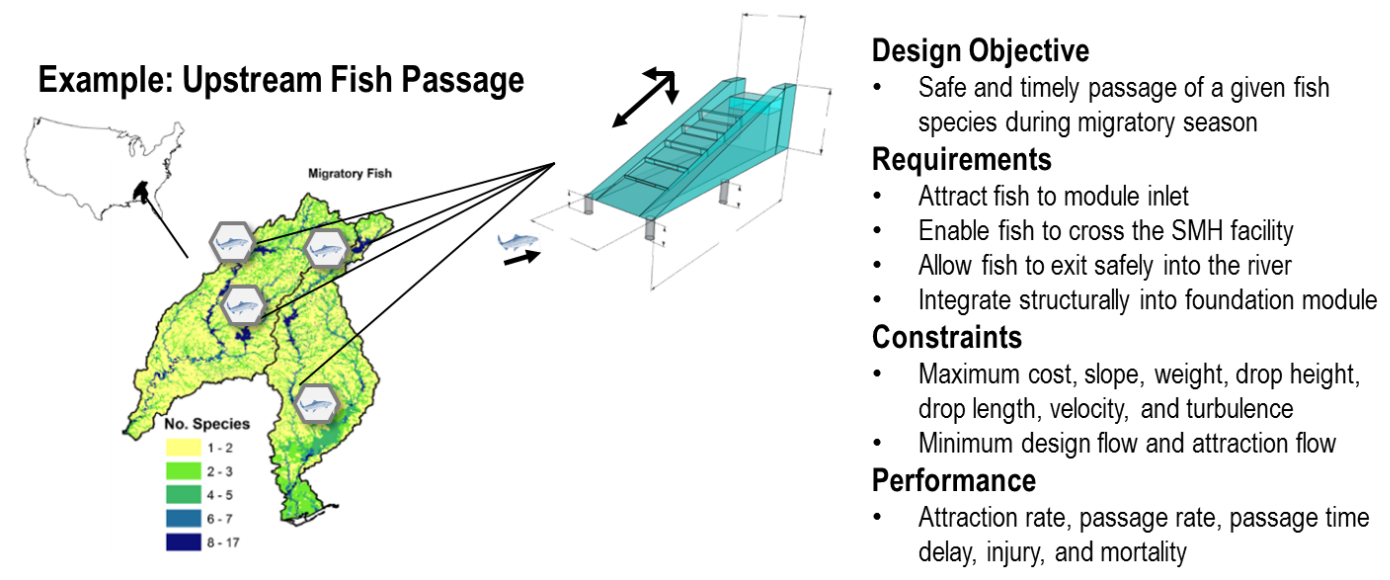

Figure 2. Example of exemplary design envelope specification for upstream fish passage modules.

The EDES discussion made clear that the SMH framework does not tell developers how to accomplish a requirement, it just specifies what the requirement is. Participants agreed with this approach, and suggested this distinction needs to be expressly defined in future interactions with industry members. Participants expressed that any effective requirement should be testable, and that a quantitative certification or pre-approval system should be developed to certify that a module has met the requirements. Other participants suggested this was beyond the capabilities of the workshop, but that it will take a sustained effort with many stakeholder groups and regulators to advance this concept. ORNL noted that the EDES seeks to establish a high level of eco-design specificity, to ensure robustness and credibility if and when the project advances to the point where regulators, nongovernmental organizations, agencies, and other environmental groups are approached to discuss SMH concepts.

\subsubsection{Testing and Validation Capability}

Adam Witt discussed the need for testing and validation of new prototype-scale technologies. He described some of the tools available at ORNL that may assist with testing and validation, including rapid prototyping using advanced manufacturing and exploration of embedded sensors for advanced module control. Most participants expressed the "first adopter" problem, in that they are challenged to find investors willing to use their technology because it has not been tested yet at prototype scale. They suggested ORNL be involved in field validation of their prototype installations.

\subsubsection{Simulation and Modeling Capability (SimCap)}

Kevin Stewart (SimCap lead) introduced the Simulation and Modeling Capabilities pillar and talked about the approach used to identify existing modeling capabilities and the respective gaps and challenges for simulation and modeling for SMH. Figure 3 illustrates how this effort is structured. Simulation use cases provide potential scenarios from which processes requiring modeling and the modeling capabilities are identified. Eight processes were identified: hydrologic, hydraulic, geomorphic, ecologic, structural, geotechnical, electromechanical, and economic. This effort reveals that whereas there are capabilities for modeling single processes, there are challenges for modeling interactions of two or more processes and for various spatial and temporal scales. The gaps and challenges are captured and prioritized in the SMH Simulation and Modeling Capability technical report ${ }^{4}$ and include composite and non-traditional material

\footnotetext{
${ }^{4}$ Stewart, K. M., B. T Smith, A. Witt, S. DeNeale, M. Bevelhimer, and J. Pries. 2017. Simulation and Modeling Capability for Standard Modular Hydropower Technology/RO ORNL/TM-2017/175, Oak Ridge National Laboratory.
} 
use, fish response quantification, watershed processes, and techno-economic cost-benefit tradeoffs. This effort provides insight into what tools are available and what research paths are necessary for addressing the gaps and challenges.

\section{Standard Modular Hydropower Simulation and Modeling Capability}

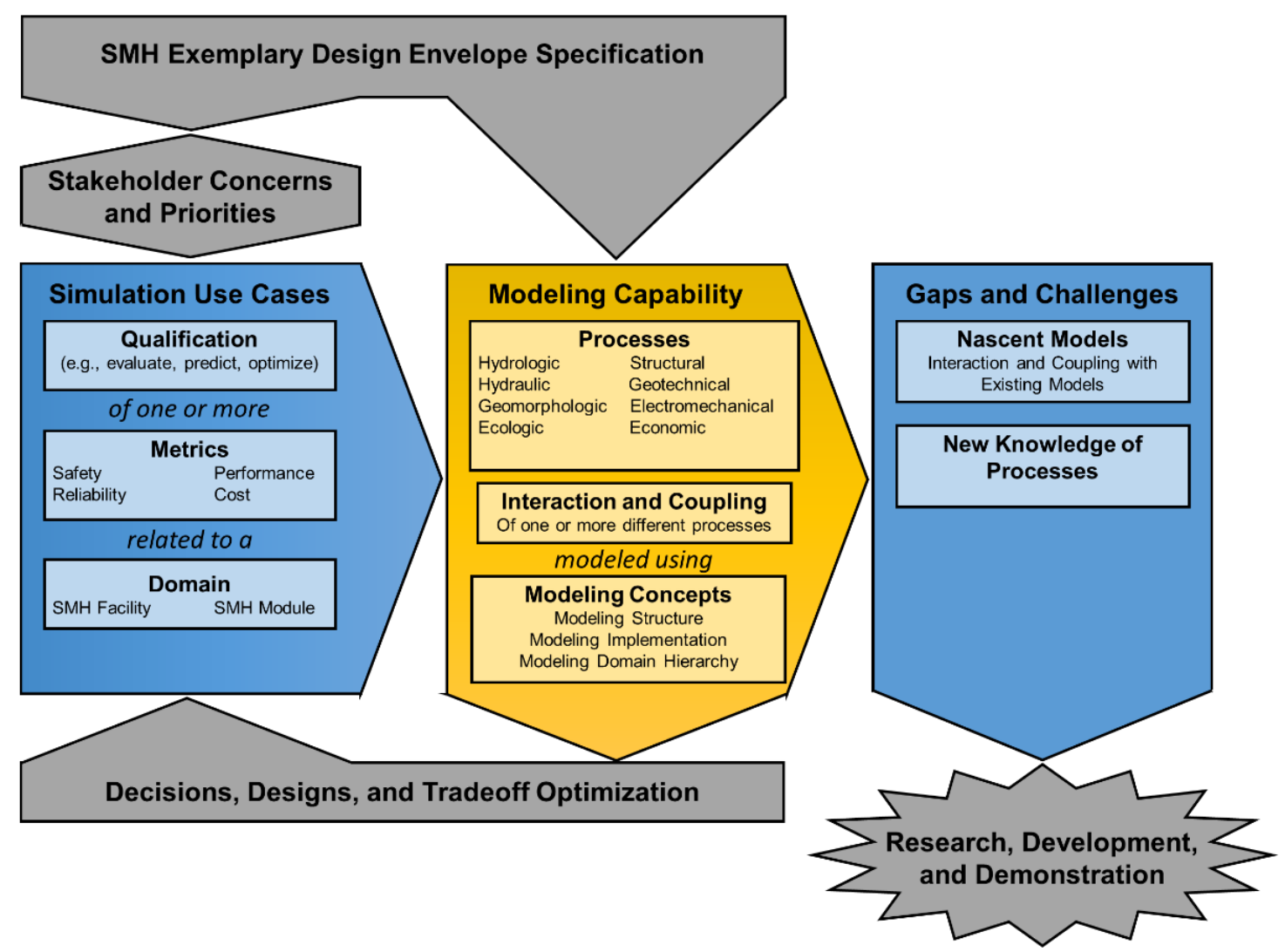

Figure 3. SimCap Flowchart.

\subsection{PARTICIPANT PERSPECTIVES}

The five industry participants were requested to bring prepared slide decks and give a brief 10 minute talk about their technologies, gaps and challenges, and goals for partnering with ORNL.

\subsubsection{Amjet Turbine Systems - Technology innovator}

Paul Roos gave an overview of Amjet's standardized turbine-generator module design. His variable speed units come in three sizes to effectively cover a large range $(5-2500 \mathrm{~kW})$ of low head (7-50 ft) hydropower applications. Using nontraditional materials allows the Amjet units to be lightweight and compact in design. Potential applications include NPD, NSD, and rehabilitation projects. Amjet is interested in utilizing additive manufacturing to produce composite and metallic components to be used in their units. 


\subsubsection{Cadens, LLC - Technology innovator}

Randal Mueller provided a technology overview of Cadens' TurbineBuilder software, a predictive design tool that uses automated numerical modeling capabilities coupled with additive manufacturing to produce semi-custom generation modules. Cadens uses S-Turbines for simplicity and allows for swappable turbine blades and other flexibilities in modularity to design a hydropower plant with minimum traditional construction methods required. Cadens is also interested in how additive manufacturing can be used to decrease equipment costs in hydropower powertrains as the technology continues to become cheaper and more advanced.

\subsubsection{Littoral Power Systems-Technology innovator and project developer}

Kathie Leighton presented an overview of the technical and design work currently being carried out at Littoral Power Systems Inc (LPS). LPS is designing a modular prefabricated run-of-river hydropower system. A kit of shop-built, standardized parts, including dam, spillway and powerhouse modules, can be assembled on-site. The kit includes a rapid-deploy seepage curtain and geotechnical package, including post-tensioning components necessary to secure the modules in accordance with applicable dam safety standards. The modules stack laterally and vertically. In most cases installation can be carried out without dewatering the stream. Levelized cost of energy (LCOE) analyses to date indicate the approach can significantly reduce civil works and maintenance costs. LPS is currently working toward pilot deployments and commercialization, but has identified a gap regarding a lack of functional test-based standards for new modular civil structure designs that could greatly assist in streamlining the regulatory pathway for modular systems.

\subsubsection{Natel Energy-Technology innovator, OEM, and project developer}

Metodi Zlatinov gave a summary of Natel's Linear Pelton hydroEngine and over-tailwater civil design. The hydroEngine retains the simplicity of a Pelton turbine but with a significantly reduced specific speed, allowing a more compact turbine design that operates at a high efficiency over a broad range of flow. The ability of the hydroEngine to operate above tailwater without cavitating further enables standardization and modularization of balance of plant. The above-tailwater approach reduces civil costs by minimizing excavation and dependence on site-specific topology, and by using precast components for the powerhouse foundation. Because of the more challenging regulatory process for developing new small hydro, Natel is initially targeting development on irrigation canal drop structures and NPDs, which generally have a lower cost and environmental barrier to entry. It is interested in applying its technology to NSD sites, which represent a much larger resource potential than NPDs or canals and conduits. Metodi emphasized Natel's focus on new projects that can provide co-benefits for ecosystems and communities.

\subsubsection{Rickly Hydrological Company-Technology innovator, OEM, and project developer}

Ryan Cook provided an overview of the three "kits" of modular hydropower systems Rickly develops for NPDs, conduits, and remote projects. Rickly also develops software to automate site assessment, determine site feasibility, and optimize hydropower designs. These products allow Rickly to assess a site and prescribe a combination of their premade modules to provide power generation at low cost.

\section{TOPICS OF INTEREST AND DISCUSSION THEMES}

Industry participant presentations and the crosstalk and Q\&A sessions that followed yielded insight into common gaps and challenges that exist among them. 


\subsection{GAPS AND CHALLENGES}

Participants were asked to identify the gaps and challenges with their designs and technology deployment strategies prior to the workshop. This feedback served as the basis for detailed discussion that took place during the workshop, and open discussion throughout the day brought out additional gaps and challenges that were applicable to many attendees. The following categories and sub-categories summarize the main themes of these discussions. While they capture the wide-ranging dialogue of the workshop, they do not necessarily represent the views of all authors or all workshop participants.

\subsubsection{Site Classification}

- Data Resolution: A gap exists between the underlying data application and approaching classification from a national level, which results in a lower resolution than a similar effort focusing at the watershed or basin level. It was clarified that this effort can provide only site classification, not selection. Mark explained how data from NHAAP and the ORNL Mitigation Predictor tool ${ }^{5}$ inform this analysis and can be useful to outside parties as well.

\subsubsection{Module and Facility Design and Operation}

- Civil Works: Currently civil works dominate small hydropower development costs due to the need for site-specific design. SMH module designs must minimize custom design for civil works to enable economic viability.

- Flow Control: The functionality of flow control is essential to the operation of many SMH applicable powertrains (guide vanes, adjustable or fixed) and passage designs (flow control at entrance). Some participants with generation modules suggested they rely on basic shutoff capabilities from a gate or valve, which stops flow completely, rather than active flow control, as a low-cost flow control solution does not currently exist for their module.

- Trash Racks: Managing debris and cleaning trash racks will be required of most SMH sites and a lowcost and low-head solution needs to be developed (e.g., a passive trash rack cleaner).

- Fish Exclusion: Identifying the type and size of fish that require passage or exclusion. Most participants rely on positive exclusion, e.g., fish screening, to prevent fish from entering their generation modules. A standard technology or method for developing fish screen characteristics (e.g., intake velocity, bar spacing, location) on generation modules would be helpful to effectively manage a large variety of fish species.

- Interconnection: To achieve modularity, the interface between electro-mechanical equipment, electrical equipment and systems, and interconnection/distribution infrastructure need to be standardized. Some participants expressed a desire to tie in to $480 \mathrm{~V}$ distribution lines rather than transmission lines because it simplified the labor requirements and enables use of standardized, offthe-shelf electrical equipment. Others suggested distance to transmission is an essential piece of their site identification methodologies.

- $\quad$ Sediment Management: It is difficult to economically justify detailed or complex sediment studies or sediment handling techniques for small facilities in the 1-5 MW range.

\footnotetext{
${ }^{5}$ http://nhaap.ornl.gov/environmental-mitigation
} 
- Geotechnical: The geotechnical conditions at a site are often unpredictable and difficult to quantify or assess without a field visit. A standard specification method for foundation modules would need to somehow address this challenge.

\subsubsection{Simulation and Modeling}

- $\quad$ Predictive Design Tools: Needed to identify good sites and to parameterize site attributes to enable formulaic plant design. However, participants agreed it is important for any automation technique to avoid replacing expert insight altogether by retaining some level of flexibility for inputs and analysis.

- $\quad$ Siting Tools: Need to be validated to ensure their effectiveness (e.g., site-truthing by going to a few sites and verifying simulation outputs).

\subsubsection{Testing and Validation}

- Design Standards: There are no design standards or guidelines that directly apply to SMH technologies. Industry must rely on other existing hydropower and civil works standards and best practices that do not guarantee regulatory acceptance for SMH applications.

- Validation: Participants stated the most probable pathway to performance validation of their full-scale technology is installation and demonstration at a pilot site. Identifying suitable pilot sites is a challenge, as few developers and financiers are willing to take a risk on a new, unproven technology,

- Surface Finish: How can the surface finish of additive manufacturing techniques be optimized for generation modules? There are some regions of a turbine blade that may require a more detailed finish, while other regions could rely on the raw output of the additive manufacturing process.

- Test Facility: Nobody is willing to buy a product until a prototype is verified, which cannot happen without installation at a site, and currently, there are no facilities to test prototype scale generation, passage, or foundation modules.

- Certification Barrier: Challenges persist in developing new certification processes, standards, and procedures for modular hydropower technology installation, operation, and assessment. Participants noted an artificial barrier may be created with new modular technologies, as stakeholders or investors may want to wait until a new certification process is complete or standard developed before signing off on new and emerging technologies

\subsubsection{Project Economics}

- SHP Economics: Small hydropower plants have a very small budget allocated to operations and maintenance and to resolving technical or environmental issues that lead to forced outages. Modular designs must emphasize reliability and minimal operations and maintenance requirements.

- New Project Costs: Bigger plants can recover costs quickly because they gain economies of scale with size and they produce more power, giving them greater revenue generation potential. Small hydropower plants do not enjoy economies of scale; furthermore, they must be competitive with wind and solar or they will not be deployed. Also, there must be a reasonable expectation of market demand to make new technologies like SMH work, and this is not currently apparent. 
- $\quad$ SMH Best Practices: Successful small hydropower project development often relies on a combination of know-how and talent. These characteristics are hard to standardize — one participant suggested a set of best practices for small modular hydropower installations would be helpful.

- Cost vs Efficiency: Do we truly know the cost of $1 \%$ efficiency improvement or decrease for small low-head hydro? Can generation modules that are less efficient than conventional machines but much less expensive be used to accelerate project deployment?

\subsubsection{Regulatory and Approval}

- License Pathways for Greenfield Small Hydro: The current regulatory process is lengthy, timeconsuming, uncertain/risky, and expensive to navigate for small hydropower developers without significant resources or development experience. Subjecting new and unproven technologies to this process as is will further strain the economics of new development.

- Regulatory Approval for First Adopters: New passage technologies installed in a stream (e.g., a new fish passage module) may face increased scrutiny from regulators and conditioning agencies if they do not have a proven track record of performance.

- $\quad$ Standards: No standards bodies exist for developing test- or performance-based standards for modular hydropower technologies.

\subsection{OPPORTUNITIES FOR SMH}

Workshop participants also proposed opportunities for SMH facilities that move beyond conventional development paradigms. They are summarized below.

- $\quad$ Standard Electrical Properties: If an electrical connection between the facility and a customer can be developed at $480 \mathrm{~V}$, it significantly reduces equipment complexity and the need for specialized electrical expertise during design and installation. One participant suggested looking for "behind-themeter" opportunities where a $480 \mathrm{~V}$ connection could enable significant cost savings on equipment and the project development/regulatory side.

- Design Flow: Designing a project using smaller flows on the flow duration curve. For example, many conventional facilities design to a flow duration of $30 \%$, or a flow that is available $30 \%$ of the time. Some participants thought designing to a flow duration as high as $95 \%$ may be an economically viable strategy that could lead to accelerated deployment.

- Site Classification: Advanced site classification tools may help alleviate the challenges of navigating the regulatory approval process by reducing the need for current, site-specific data and studies.

ORNL's Site Classification research is developing a framework for classifying potential SMH sites in terms useful for informing module needs and design requirements using existing and new classification schemes. Some participants stated attempts to apply historic data and studies to potential new sites have been largely unsuccessful. A standard site classification method that feeds an environmental design specification for many sites would be a helpful development tool.

- Sensor Technology: Embedded sensors can be utilized to monitor performance metrics and machine/structure condition at an SMH facility, providing useful information to operations and maintenance decision makers. Embedded sensor technology can be used to automate module 
operation across the facility, enabling "smart" modules that automatically respond to dynamic environmental or power system conditions.

- Water Quality: One participant suggested SMH facilities may provide water quality improvements in urban or agricultural streams with small aerating turbines or weirs. These opportunities need to be identified to allow the development of standard facility designs to improve certain water quality deficiencies

- Case Studies: All the participants supported an SMH effort to explore initial case studies that laid design specifications at a few different sites. The initial site classification need for each site was defined as a combination of site attributes (e.g., head, gradient, flow and duration curves, geometry, topology, fish species present, water quality). The discussion promoted the importance of fatal flaw analysis to immediately identify major issues that might make the project unfeasible. Participants also expressed a desire to assess three classes of facilities at each site: bank-to-bank modular facility development, partially submerged modular facility development, and diversion modular development with the balance of infrastructure located along the bank. The goals for this effort would be to develop a preliminary standardized specification for a few different sites, to gain a better understanding of research and industry needs through collaboration, and to provide valuable benchmarks that can be used in discussions with new and diverse stakeholder groups.

- $\quad$ Additive Manufacturing: Several participants expressed interest in using advanced manufacturing and $3 \mathrm{D}$ printing in the manufacturing and prototyping of their technologies. Most were focused on turbine units, such as printing small components, major components (e.g., runner blades), and entire turbine assemblies. One participant was interested in printing the turbine unit with water conveyance.

- Multiple Dimensions of Collaboration: Participants agreed that SMH technologies should be advanced through multiple collaboration mechanisms. A consortium of modular technology developers was suggested as a way to share new ideas and develop cohesive narratives for approaching regulatory and approval stakeholders. Specific collaborative research and development agreements with ORNL may also be used to apply emerging lab technologies to specific modular designs. Finally, working groups for individual modules were proposed as a way to establish common objectives and identify where there are gaps in existing standards that may be applied to SMH modules and facilities.

- $\quad$ Applicability to Non-powered Dams: Many participants agreed the SMH concept would also work well at NPDs, and these may be the first realistic opportunities to deploy modular technologies. There is a common need for a classification system for existing NPDs (type of dam, type of likely development, head, flow, environmental attributes, etc.) that could broadly inform the design requirements of modular NPD development.

\section{ORNL CAPABILITIES AND APPLICABILITY FOR SMALL HYDROPOWER}

The second day of the workshop was characterized by a series of short presentations showcasing the wide variety of ORNL capabilities. Staff members made presentations on BioDesign, Power Electronics and Electric Machinery, Additive and Composite Manufacturing, Sensors and Embedded Sensors, and Computational Engineering and Energy. 


\subsection{BIO DESIGN}

Mark Bevelhimer presented ORNL's capabilities in BioDesign. A hydropower related project currently being conducted at ORNL is researching biology-informed turbine design and how fish interact with different runner blades (Figure 4). The project assesses injuries and mortality rates to find what characteristics of turbines cause the most harm to fish. Mark covered the different design tools and evaluation techniques used in the project such as BioPA, a software that uses computational fluid dynamics (CFD) models of particles being passed through a turbine and sensor fish for physical testing. A brief discussion about how each industry participant is currently or planning to pass or exclude fish ensued.
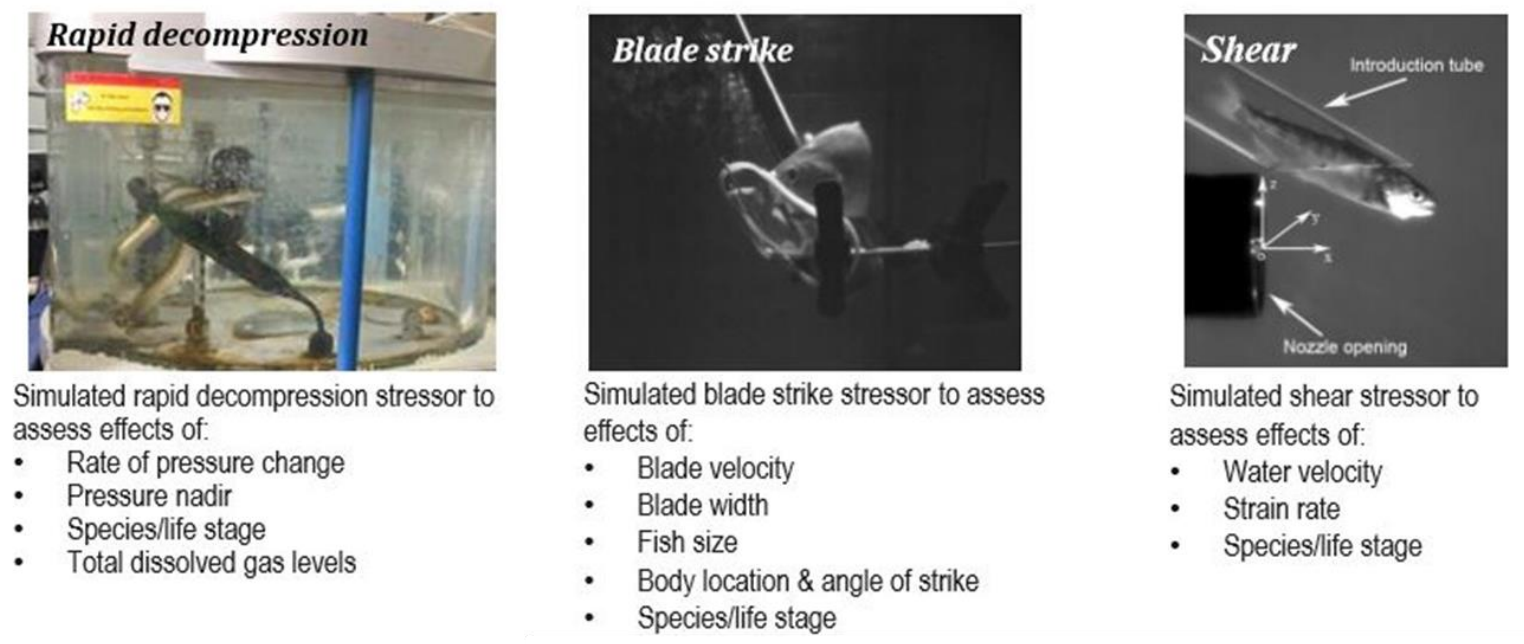

Figure 4. Examples of BioDesign laboratory experiments to assess fish injury due to turbine stressors.

\subsection{POWER ELECTRONICS AND ELECTRIC MACHINERY}

Jason Pries, ORNL Power Electronics and Elec Machinery Group, gave an overview of ORNL's capabilities in power electronics and electric machinery. The group focuses on electric motor generator technology, exploring new ways to optimize cost with increased power and torque density. Jason explained how the primary driver of cost is the materials, specifically the rare-earth materials traditionally used. Therefore, the group is exploring new methods and materials to produce a more cost-effective, usable motor. Jason noted the importance to design to the optimal efficiency region (i.e., the rpm range the electric motor will most frequently operate in) and how this line of thinking could translate small hydropower technology.

\subsection{ADDITIVE AND COMPOSITE MANUFACTURING}

Lonnie Love, ORNL Manufacturing Systems Research Group, provided an overview of the additive and composite manufacturing capabilities that are present at ORNL's Manufacturing Demonstration Facility (MDF). Lonnie covered the variety of applications and projects to which his group have applied additive manufacturing and 3D printing, as well as the many types of advanced manufacturing and 3D printing technologies that exist, each with associated its associated material type, unit and operational costs, and size capability.

Lonnie emphasized that complexity is not free and that 3D printing is generally not suited for mass production (1,000 or greater parts) unless the design is overly complex. Rather, he sees the "killer app" of $3 \mathrm{D}$ printing as cheap and quick production of tooling and molds that can be used in traditional 
manufacturing processes. Lonnie described ongoing work between ORNL/MDF and Emrgy Hydro ${ }^{6}$, a hydrokinetic turbine developer, to 3D print both a complex gearhouse ${ }^{7}$ and turbine blade molds (Figure $5)$.

Workshop participants all expressed interest in the technology and how it could be utilized in prototyping and tooling for turbine components and assemblies.

\section{Emrgy}

- Using AM to manufacture patterns for castings

- First made pattern for AICe pump housing

- Printing mold and cast housing

- Currently making pattern using BAAM for blades

- Cost for tooling was killing their project
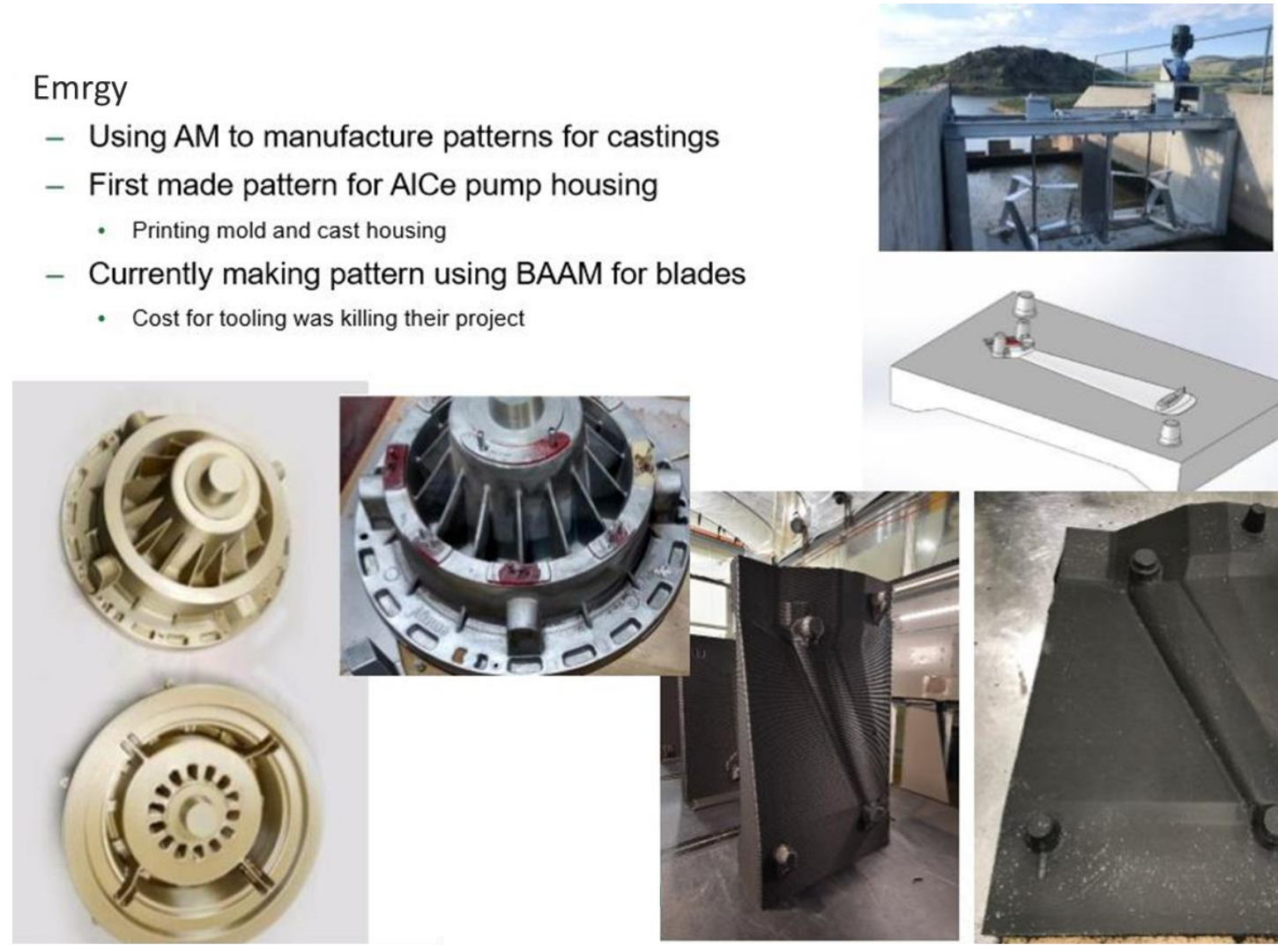

Figure 5. Examples of AM being used in small hydropower development.

\subsection{SENSORS AND EMBEDDED SENSORS}

Yarom Polsky, ORNL Sensors and Embedded Systems Group, presented the past and current work ORNL is doing with sensor, data logging, and signal analysis technology. Measurement research is being done at ORNL for many applications from nuclear to environmental monitoring. Yarom stressed that incorporating sensor technology and building electrical signatures into the design at the beginning is very helpful to detect failure modes, such as vibration analysis of a turbine unit, during its lifetime.

Commonly, sensor technology and signal analysis are performed on a system after a problem is detected, which makes it difficult for the team doing the analysis to understand the system fully.

\subsection{COMPUTATIONAL ENGINEERING AND ENERGY SCIENCES}

Srikanth Allu, ORNL Computational Engineering and Energy Sciences Group, talked about the highperformance computing for manufacturing ( $\mathrm{HPC} \mathrm{Mfg}^{8}$ ) Advanced Manufacturing Office (AMO) funding

${ }^{6}$ http://emrgy.com/

7 https://www.ornl.gov/news/tooling-repeating-pattern 
opportunity, and how the program leverages advanced fluid modeling and supercomputer capabilities at ORNL. The HPC4Mfg partners with industry to use the ORNL's supercomputers to improve processes and develop models on projects related to science or energy.

Prashant Jain, ORNL Thermal Hydraulics and Irradiation Engineering Group, continued the presentation with a focus on additional CFD modeling capabilities. Prashant explained how conventional finite volume method codes are being used to support engineering design and optimization as well as how hybrid multiphysics CFD modeling and simulation have been successfully used on industry applications.

Prashant talked about the Oak Ridge Siting Analysis for power Generation Expansion, or OR-SAGE ${ }^{9}$, which is a technology designed to streamline the siting process for power plants. OR-SAGE is a visualization database that factors in an array of variables and geographic information system (GIS) data to allow the user to look at power potential at the national level through a lens. Prashant explained that the code is open source and could be applicable to assist in site classification for hydropower plants with DOE approval. The discussion touched on the gaps of accurate CFD modeling of rotating turbines and fish-turbine interactions in addition to the lack of a verification process in the hydropower industry to move from an analytical model to a product.

\section{WORKSHOP SUMMARY}

On behalf of DOE and the ORNL team, Adam Witt thanked the participants for attending a workshop that brought together a broad a cross section of experience, opinions, and ideas to the SMH project.

Participants gained an understanding of the SMH project as well as the many technological capabilities available at ORNL and potential partnership pathways. The SMH team elicited valuable feedback and mediated crosstalk with industry members on SMH research challenges, offering validation of some concepts and identifying areas of improvement for others. The workshop made evident the knowledge and capability gaps that currently exist in both the research and industry realms. These, documented herein, will be useful in determining future research efforts, industry collaboration, tool development, and modular technology advancement.

${ }^{8}$ https://hpc4mfg.llnl.gov/

9 https://www.ornl.gov/news/ornl-tool-puts-spotlight-nation-s-electricity-generation-capacity 



\section{APPENDIX A. WORKSHOP PARTICIPANTS}

\begin{tabular}{|c|c|}
\hline Attendee & Organization \\
\hline Adam Witt & ORNL \\
\hline Alisha Fernandez & McKeown \& Associates \\
\hline Brennan Smith & ORNL \\
\hline David Duquette & Littoral Power Systems \\
\hline Hailey Russell & ORNL \\
\hline Jason Pries & ORNL \\
\hline Josh Benjamin & ORNL \\
\hline Katherine Leighton & Littoral Power Systems \\
\hline Kevin Stewart & ORNL \\
\hline Lonnie Love & ORNL \\
\hline Mark Bevelhimer & ORNL \\
\hline Mark Reeves & ORNL \\
\hline Mat Garrett & ORNL \\
\hline Metodi Zlatinov & Natel Energy \\
\hline Miles Mobley & ORNL \\
\hline Nestor Franco & ORNL \\
\hline Norm Bishop & Knight Piesold \\
\hline Patrick O'Connor & ORNL \\
\hline Paul Roos & Amjet Turbine Systems \\
\hline Prashant Jain & ORNL \\
\hline Randal Mueller & Cadens \\
\hline Ryan Cook & Rickly Hydrological Company \\
\hline Scott DeNeale & ORNL \\
\hline Shelaine Curd & ORNL \\
\hline Srikanth Allu & ORNL \\
\hline Will Tingen & ORNL \\
\hline Yarom Polsky & ORNL \\
\hline
\end{tabular}




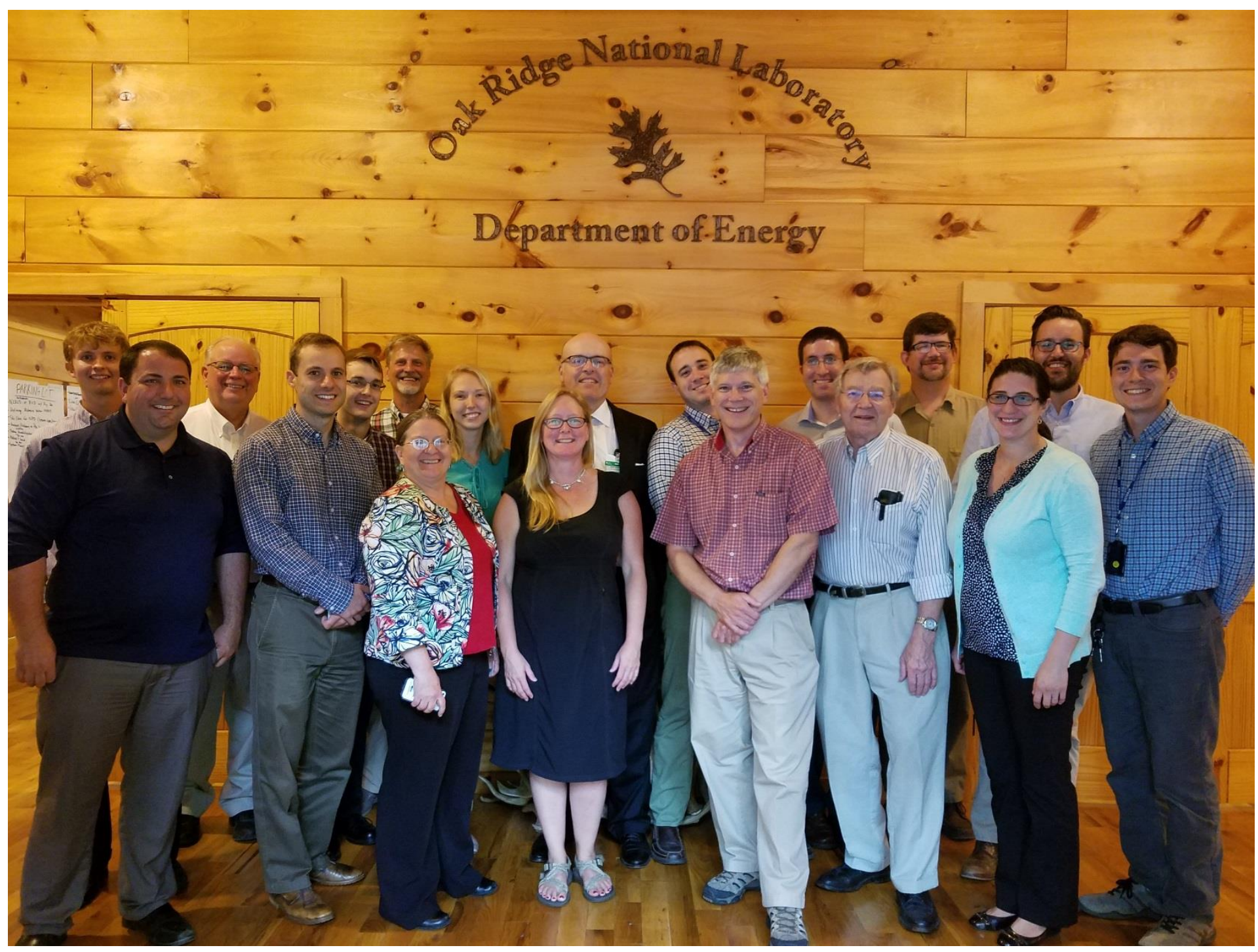

Figure 6. Workshop Day 1 participants. From left to right: Josh Benjamin, Ryan Cook, Norm Bishop, Metodi Zlatinov, Will Tingen, Randal Mueller, Kathie Leighton, Hailey Russel, Shelaine Curd, David Duquette, Patrick O’Connor, Mark Bevelhimer, Scott DeNeale, Paul Roos, Brennan Smith, Alisha Fernandez, Adam Witt, Miles Mobley. 


\section{APPENDIX B. WORKSHOP AGENDA}

Standard Modular Hydropower Technology Acceleration Workshop: Summary Report Oak Ridge, TN

June 14 - 15, 2017

\begin{tabular}{|c|c|c|}
\hline \multicolumn{3}{|c|}{ Wednesday, June 14, 2017} \\
\hline Time (ET) & Event/Activity & Lead \\
\hline \multicolumn{3}{|c|}{ SMH Technology Concepts } \\
\hline 8:30-9:40am & $\begin{array}{l}\text { Attendee Introductions and } \\
\text { Workshop Purpose \& Objectives }\end{array}$ & Adam Witt \\
\hline 9:40-10:00am & 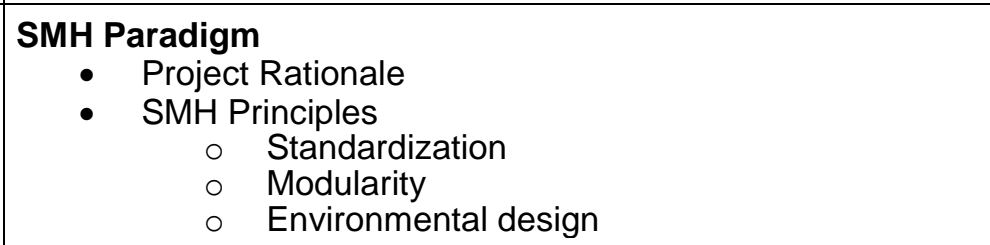 & Adam Witt \\
\hline 9:40-10:30am & 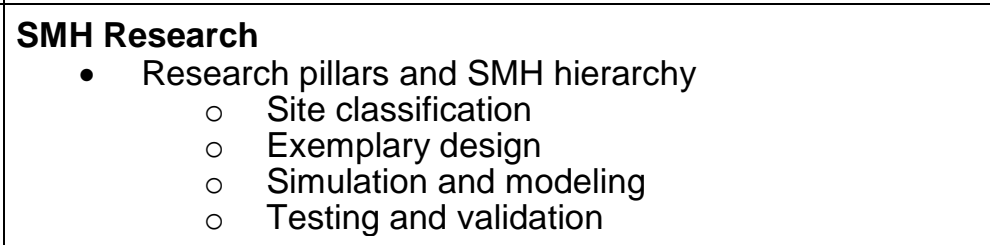 & $\begin{array}{l}\text { Adam Witt } \\
\text { Mark Bevelhimer } \\
\text { Kevin Stewart }\end{array}$ \\
\hline 10:40-11:40am & $\begin{array}{l}\text { Participant Perspectives "Round Robin" } \\
\text { - Technology Overview } \\
\text { - Gaps and Challenges } \\
\text { - Goals for Partnering with ORNL }\end{array}$ & $\begin{array}{l}\text { Participants } \\
\text { (10-min each) }\end{array}$ \\
\hline 11:40-1:00pm & $\begin{array}{l}\text { WORKING LUNCH: } \\
\text { Functionality-Technology Mapping Exercise } \\
\text { - What functionalities are provided by the modular design of } \\
\text { each attendee? } \\
\text { - What functionalities are missing from modular design of } \\
\text { each attendee? }\end{array}$ & $\begin{array}{l}\text { Adam Witt } \\
\text { Alisha Fernandez }\end{array}$ \\
\hline \multicolumn{3}{|c|}{ Brainstorming of Knowledge Gaps and Capability Mapping } \\
\hline 1:10-2:10pm & $\begin{array}{l}\text { Knowledge Gaps in Site Classification } \\
\text { - ORNL gaps in site classification } \\
\text { - What are industry gaps in site classification? } \\
\text { Capability Mapping and Brainstorming } \\
\text { - What capabilities are needed to fill gaps and challenges? } \\
\text { - Where can collaboration bridge gaps? }\end{array}$ & $\begin{array}{l}\text { Mark Bevelhimer } \\
\text { Adam Witt }\end{array}$ \\
\hline
\end{tabular}




\begin{tabular}{|c|c|c|}
\hline \multicolumn{3}{|c|}{ Wednesday, June 14, 2017} \\
\hline Time (ET) & Event/Activity & Lead \\
\hline 2:10-3:10pm & $\begin{array}{l}\text { Knowledge Gaps in Exemplary Design } \\
\text { - ORNL gaps in exemplary design } \\
\text { - What are industry gaps in exemplary design? } \\
\text { Capability Mapping and Brainstorming } \\
\text { - What capabilities are needed to fill gaps and challenges? } \\
\text { - Where can collaboration bridge gaps? }\end{array}$ & Adam Witt \\
\hline \multicolumn{3}{|c|}{ Collaboration Opportunities } \\
\hline 3:20-3:45pm & Collaboration Framework & Brennan Smith \\
\hline 3:45-4:05pm & Collaboration Mechanisms & $\begin{array}{l}\text { Nestor Franco } \\
\text { Mark Reeves } \\
\text { Mat Garrett }\end{array}$ \\
\hline 4:05-4:30pm & $\begin{array}{l}\text { Priority Challenges and Opportunities } \\
\text { - Identify the most critical pathways toward increasing small } \\
\text { hydropower deployment within the SMH Paradigm }\end{array}$ & Adam Witt \\
\hline $4: 30-4: 45 p m$ & Day 1 Recap with Q\&A & Adam Witt \\
\hline 4:45-5:00pm & Day 2 Preview of ORNL Capabilities Focus Areas & Adam Witt \\
\hline
\end{tabular}

\begin{tabular}{|c|l|l|}
\hline \multicolumn{2}{|c|}{ Thursday, June 15, 2017 } & \multicolumn{1}{|c|}{ Lead } \\
\hline Time (ET) & \multicolumn{1}{|c|}{ Event/Activity } & Adam Witt \\
\hline 8:30-9:00am & Agenda Review and Day 1 Reflections & Mark Bevelhimer \\
\hline \multicolumn{1}{|c|}{ ORNL Capabilities and Collaboration Opportunities } & Jason Pries \\
\hline 9:00-9:20am & BioDesign & Lonnie Love \\
\hline 9:20-9:50am & Power Electronics and Electric Machinery & Yarom Polsky \\
\hline 9:50-10:30am & Additive \& Composite Manufacturing & \\
\hline 10:40-11:10am & Sensors and Embedded Sensors &
\end{tabular}




\begin{tabular}{|c|l|c|}
\hline \multicolumn{2}{|c|}{ Thursday, June 15, 2017 } \\
\hline Time (ET) & \multicolumn{1}{|c|}{ Event/Activity } & \multicolumn{1}{|c|}{ Lead } \\
\hline $11: 10-11: 40 \mathrm{am}$ & Computational Engineering \& Energy Sciences & $\begin{array}{l}\text { Srikanth Allu } \\
\text { Prashant Jain }\end{array}$ \\
\hline $11: 40-1: 00 \mathrm{pm}$ & $\begin{array}{l}\text { WORKING LUNCH: } \\
\text { Workshop Summary and Next Steps }\end{array}$ & Adam Witt \\
\hline
\end{tabular}


